Article

\title{
Insecticidal and Attractant Activities of Magnolia citrata Leaf Essential Oil against Two Major Pests from Diptera: Aedes aegypti (Culicidae) and Ceratitis capitata (Tephritidae) ${ }^{\dagger}$
}

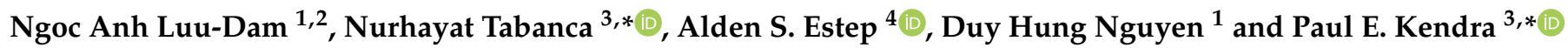 \\ 1 Vietnam Academy of Science and Technology (VAST), Graduate University of Science and Technology, No. 18 \\ Hoang Quoc Viet Road, Cau Giay District, Hanoi 100803, Vietnam; ngocanh@vnmn.vast.vn (N.A.L.-D.); \\ bochunghg@gmail.com (D.H.N.) \\ 2 Vietnam National Museum of Nature, Vietnam Academy of Science and Technology (VAST), No.18 Hoang \\ Quoc Viet Road, Cau Giay District, Hanoi 100803, Vietnam \\ 3 United States Department of Agriculture-Agricultural Research Service (USDA-ARS), Subtropical \\ Horticulture Research Station (SHRS), 13601 Old Cutler Rd., Miami, FL 33158, USA \\ 4 United States Department of Agriculture-Agricultural Research Service (USDA-ARS), Center for Medical, \\ Agricultural, and Veterinary Entomology (CMAVE), Gainesville, FL 32608, USA; alden.estep@usda.gov \\ * Correspondence: nurhayat.tabanca@usda.gov (N.T.); paul.kendra@usda.gov (P.E.K.) \\ + This work was produced by US government employees and is in the public domain in the US.
}

Citation: Luu-Dam, N.A.;

Tabanca, N.; Estep, A.S.;

Nguyen, D.H.; Kendra, P.E. Insecticidal and Attractant Activities of Magnolia citrata Leaf Essential Oil against Two Major Pests from Diptera: Aedes aegypti (Culicidae) and Ceratitis capitata (Tephritidae) . Molecules 2021, 26, 2311. https:// doi.org $/ 10.3390 /$ molecules 26082311

Academic Editors: Ladislav Kokoska and Laura De Martino

Received: 22 March 2021

Accepted: 14 April 2021

Published: 16 April 2021

Publisher's Note: MDPI stays neutral with regard to jurisdictional claims in published maps and institutional affiliations.

Copyright: $\odot$ This work was produced by US government employees and is in the public domain in the US. Sub-mitted for possible open access publication under the terms and conditions of the Creative Com-mons Attribution (CC BY) license (https:// creativecommons.org/licenses/by/ $4.0 /)$.

\begin{abstract}
In this study, Magnolia citrata Noot and Chalermglin (Magnoliaceae) essential oil (MCEO) was evaluated for insecticidal activity against the yellow fever mosquito Aedes aegypti and attractant activity for the Mediterranean fruit fly Ceratitis capitata. The leaves of Magnolia citrata (Giổi chanh) were collected from northwestern Vietnam, and the water-distilled MCEO was analyzed by gaschromatography and mass spectrometry (GC-MS). The major constituents of MCEO were identified as linalool $19 \%$, geranial $16 \%$, citronellal $14 \%$, neral $14 \%$, and sabinene $12 \%$. MCEO showed $100 \%$ mortality at $1 \mu \mathrm{g} / \mu \mathrm{L}$ against 1st instar larvae of Ae. aegypti (Orlando strain, ORL), and the oil exhibited $54 \%$ (ORL) and $68 \%$ (Puerto Rico strain) mortality at $5 \mu \mathrm{g} /$ mosquito against Ae. aegypti adult females. Initial screens showed that MCEO had weak insecticidal activity compared to the positive control permethrin. In bioassays with sterile male C. capitata, MCEO exhibited moderately strong attraction, comparable to that observed with a positive control, Tetradenia riparia essential oil (TREO). Herein, the insecticidal and attractant activities of MCEO are reported for the first time.
\end{abstract}

Keywords: Magnoliaceae; mosquito; medfly; fruit fly; GC-MS; aliphatic aldehydes; citronellal; geranial; citral

\section{Introduction}

The extensive and long-term application of pesticides has resulted in an accumulation of residues in food, water, soil, and other environmental components. The negative impact of pesticides on biodiversity, and increasing pesticide resistance, have prompted more research on alternative control strategies using botanicals, biological, cultural, and other sustainable methods for integrated management of existing and invasive pests [1-6]. Plants synthesize a diverse array of molecules that can be exploited to develop novel pest control agents [7-9]. Vietnam is a tropical Asian country with extraordinarily rich plant biodiversity, and many of the indigenous plants are known to have medicinal properties; the country's rich forest ecosystems provide an abundant opportunity to search for phytochemicals with potential applications for the management of major insect pest species [10-12]. Aedes aegypti L. (Diptera: Culicidae) mosquitoes are the major vector for the transmission of several uncontrolled, life-threatening viral diseases, which are more frequent in hot and humid climate regions [13,14], and thus effective mosquito control of both larval and adult stages can reduce the impact of vector-borne diseases. As an 
economically important agricultural pest, the Mediterranean fruit fly, Ceratitis capitata (Wiedemann) (Diptera: Tephritidae), is one of the most serious invasive pests in tropical and subtropical regions around the world [15]. It attacks a wide range of fruits and vegetables, with larval infestation causing severe damage to many commercially important tropical and subtropical crops [16,17]. Thus, identification of effective attractants for early detection and suppression of $C$. capitata populations is critical for managing this pest and reducing crop losses.

The genus Magnolia L. (Magnoliaceae) is one of the oldest families of flowering plants [18]. The genus comprises about 245 taxa occurring in temperate and tropical areas of Southeast and East Asia, North America, the Antilles, and Central and South America [19]. Magnolia species have attracted a great deal of research interest due to the presence of biphenolic phytochemicals magnolol and honokiol, which possess diverse pharmacological properties, including inhibition of the central nervous system, prevention of cardiovascular disease, anti-inflammatory, antimicrobial, antioxidative, and free radical scavenging activity [20-22]. Magnolia extracts and their bioactive chemicals have been evaluated for their promising insecticidal activity. A lignan, epimagnoline A, was isolated from flower buds of M. fargesii (Finet and Gagnep.) [23]. Larvicidal activity of different solvent extracts of M. salicifolia Maxim. showed good to moderate effect on fourth instar larvae of Aedes aegypti [24]. Essential oils from $M$. grandiflora L. were tested for insecticidal and biting deterrent activity against $A e$. aegypti, and the seed oil exhibited biting deterrence similar to the standard insect repellent DEET ( $N, N$-diethyl-3-methylbenzamide) [25]. Tests for insecticidal susceptibility to ethanol extracts from M. dealbata Zucc. [26] and M. schiedeana Schltl. were carried out against the tephritid fruit fly Anastrepha ludens (Loew) [27]. Sarcotesta extract from $M$. dealbata [26], as well as the seed and sarcotesta extracts from M. schiedeana, showed potential insecticidal activity against adults of $A$. ludens [27]. Magnolia citrata Noot and Chalermglin is an evergreen tree (Figure 1) that grows naturally in three localities in Thailand and at one locality in Vietnam [28-30]. Leaves are locally known as Giổi chanh' due to strong citrus or lemongrass odor and used as spices in traditional food preparations by the people of Ha Giang [31]. In a search for biorational insecticidal agents from natural sources that could be useful in future pest management strategies, we (i) isolated $M$. citrata essential oil (MCEO) from leaves, (ii) identified the chemical content of MCEO, (iii) evaluated MCEO for potential insecticidal activity against larval and adult $A e$. aegypti, and (iv) assayed MCEO for potential attraction of sterile male $C$. capitata. This study represents the first investigation of MCEO for insecticidal and attractant properties.

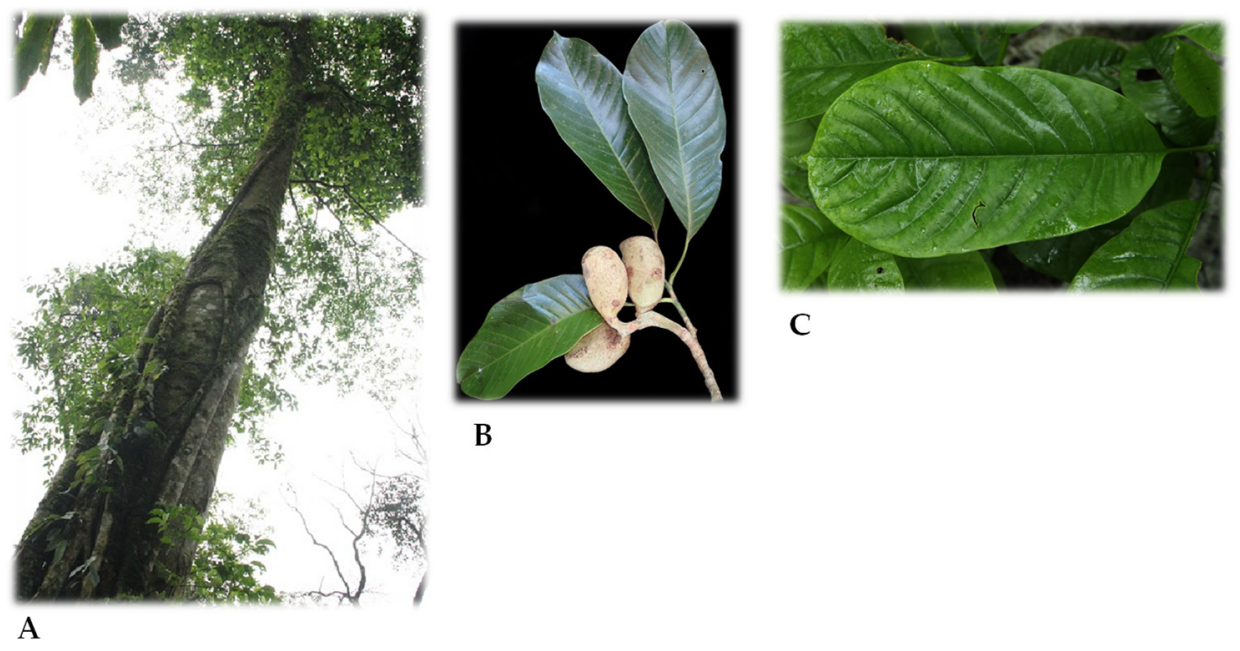

Figure 1. (A) General view of Magnolia citrata Noot and Chalermglin; (B): leaves with young fruit; (C) mature leaves of M. citrata. Photos courtesy of Mrs. Tu Bao Ngan and Mr. Bui Văn Hương. Photos provided by N.A.L-D. 


\section{Results and Discussion}

The gas chromatography-mass spectrometry (GC-MS) analysis of MCEO using a nonpolar column revealed the presence of 41 chemical components with a composition of $98 \%$ (Table 1). The major compounds of MCEO were identified as linalool $19.1 \%$, geranial $15.7 \%$, citronellal $14.1 \%$, neral $13.5 \%$, and sabinene $12.4 \%$. The MCEO was dominated by oxygenated monoterpenoids $(77.8 \%)$, followed by monoterpene hydrocarbons $(17.3 \%)$, sesquiterpene hydrocarbons $(0.8 \%)$, oxygenated sesquiterpenes $(0.3 \%)$, and others $(1.8 \%)$.

Magnolia citrata is listed under the International Union for Conservation of Nature (IUCN) Red List criteria as Least Concern (LC) category [30]. To avoid extinction and to conserve $M$. citrata in Vietnam, MCEO composition has been poorly explored despite its distinctive odor [31]. The existing literature showed that MCEO was rich in linalool, citronellal, and citral isomers (neral and geranial) [32], which corresponds with our results.

Table 1. Chemical composition of Magnolia citrata oil (MCEO).

\begin{tabular}{|c|c|c|c|c|}
\hline $\mathrm{RI}^{\mathrm{a}}$ & $\mathbf{R I}^{\mathbf{b}}$ & Compounds & $\%$ & Identification Method a,c,d \\
\hline 851 & 850 & (Z)-3-hexen-1-ol & 0.6 & MS, RI, std \\
\hline 920 & 924 & $\alpha$-thujene & 0.4 & MS, RI \\
\hline 926 & 932 & $\alpha$-pinene & 0.1 & MS, RI, std \\
\hline 968 & 969 & sabinene & 12.4 & MS, RI, std \\
\hline 971 & 974 & $\beta$-pinene & 0.5 & MS, RI, std \\
\hline 981 & 981 & 6-methyl-5-hepten-2-one & 1.2 & MS, RI, std \\
\hline 985 & 988 & myrcene & 0.4 & MS, RI, std \\
\hline 1020 & 1020 & $p$-cymene & 0.8 & MS, RI, std \\
\hline 1024 & 1024 & limonene & 0.4 & MS, RI, std \\
\hline 1026 & 1026 & 1,8-cineole & 0.3 & MS, RI, std \\
\hline 1032 & 1032 & $(Z)$ - $\beta$-ocimene & 1.2 & MS, RI, std \\
\hline 1043 & 1044 & $(E)$ - $\beta$-ocimene & 0.1 & MS, RI, std \\
\hline 1053 & 1054 & $\gamma$-terpinene & 0.1 & MS, RI, std \\
\hline 1064 & 1065 & cis-sabinene hydrate & 0.9 & MS, RI \\
\hline 1082 & 1067 & cis-linalool oxide (furanoid) & 0.3 & MS, RI, std \\
\hline 1101 & 1095 & linalool & 19.1 & MS, RI, std \\
\hline 1107 & 1118 & cis- $p$-menth-2-en-1-ol & 0.1 & MS, RI, std \\
\hline 1120 & 1136 & trans- $p$-menth-2-en-1-ol & 0.1 & MS, RI, std \\
\hline 1137 & 1144 & neo-isopulegol & 0.1 & MS, RI \\
\hline 1142 & 1145 & isopulegol & 0.8 & MS, RI \\
\hline 1150 & 1148 & citronellal & 14.1 & MS, RI \\
\hline 1157 & 1167 & neoiso-isopulegol & 0.1 & MS, RI \\
\hline 1165 & 1173 & rosefuran epoxide & 0.1 & MS, RI \\
\hline 1174 & 1174 & terpinen-4-ol & 1.6 & MS, RI, std \\
\hline 1190 & 1186 & $\alpha$-terpineol & 0.2 & MS, RI, std \\
\hline 1220 & 1227 & nerol & 0.4 & MS, RI \\
\hline 1226 & 1223 & citronellol & 6.5 & MS, RI, std \\
\hline 1235 & 1235 & neral & 13.5 & MS, RI \\
\hline 1245 & 1249 & piperitone & 0.1 & MS, RI, std \\
\hline 1252 & 1257 & methyl citronellate & 0.9 & MS, RI \\
\hline 1265 & 1264 & geranial & 15.7 & MS, RI \\
\hline 1268 & 1271 & citronellyl formate & 0.4 & MS, RI \\
\hline 1323 & 1312 & citronellic acid & 3.4 & MS, RI \\
\hline 1405 & 1417 & $\beta$-caryophyllene & 0.1 & MS, RI, std \\
\hline 1439 & 1452 & $\alpha$-humulene & $\operatorname{tr}$ & MS, RI, std \\
\hline 1443 & 1458 & alloaromadendrene & 0.2 & MS, RI, std \\
\hline 1472 & 1489 & $\beta$-selinene & 0.4 & MS, RI \\
\hline 1480 & 1498 & $\alpha$-selinene & 0.1 & MS, RI \\
\hline 1562 & 1582 & caryophyllene oxide & 0.3 & MS, RI, std \\
\hline 1584 & 1602 & ledol & $\operatorname{tr}$ & MS, RI \\
\hline 1589 & 1608 & humulene epoxide II & $\operatorname{tr}$ & MS, RI \\
\hline
\end{tabular}

a RI: retention indices calculated on DB-5MS; ${ }^{b} \mathrm{RI}_{\text {lit }}$ : retention indices from Adams Library [33]; tr: trace < 0.1 c MS: identified on the basis of computer matching of the mass spectra with those of the Adams Library [33], NIST [34], Wiley [35], MassFinder [36], FFNSC 3 libraries [37]; ${ }^{\mathrm{d}}$ std: authentic compounds on the DB-5MS column.

Initial larval activity testing MCEO against 1st instar Ae. aegypti (Orlando, ORL strain, insecticide-susceptible) showed $100 \%, 40 \%, 20 \%$, and $0 \%$ mortality at the concentration of $1.0,0.5,0.25$, and $0.1 \mu \mathrm{g} / \mu \mathrm{L}$, respectively, while positive control permethrin had $100 \%$ 
mortality at $31 \mathrm{pg} / \mu \mathrm{L}$ and solvent control (DMSO) showed $0 \%$ mortality. In adult topical bioassays, MCEO was tested against female Ae. aegypti (ORL and Puerto Rico (PR) strain (pyrethroid-resistant) ) and the oil demonstrated $53.89 \%( \pm 23.35)$ and $67.65 \%( \pm 17.74)$ mortality at $5 \mu \mathrm{g} / \mathrm{mosquito}$, respectively. Permethrin showed $60 \%( \pm 20)$ mortality of the ORL and $10 \%( \pm 10)$ mortality against the PR strain at $0.69 \mathrm{ng} / \mu \mathrm{L}$. Control mortality of solvent (acetone) was $0 \%$.

MCEO demonstrated 100\% mortality at $1 \mu \mathrm{g} / \mu \mathrm{L}(1000 \mathrm{ppm})$ against 1 st instar larvae while the activity dropped quickly at lower concentrations. Previous studies of larvicidal activity of dominant compounds in MCEO were investigated against Ae. aegypti larvae, and they exhibited good to moderate activity. For example, the larvicidal activity of citral, which contains geranial and neral, showed 100\% mortality at $100 \mathrm{ppm}$ in $24 \mathrm{~h}$ against 4 th instar Ae. aegypti [24]. Pandey et al. [38] reported that linalool displayed 100\% mortality at $200 \mathrm{ppm}$ in $24 \mathrm{~h}$ post-treatment against 4th instar larvae of Ae. aegypti. Waliwitiya et al. [39] have also reported that citronellal exhibited larvicidal activity against all four larval stages of Ae. aegypti ( $\mathrm{LC}_{50}$ values 10.3-40.8 mg/L). Cheng et al. [40] found that sabinene had larvicidal activity at $\mathrm{LC}_{50}$ of $74.1 \mathrm{mg} / \mathrm{mL}$ against fourth-instar larvae after $24 \mathrm{~h}$ treatment. MCEO is not considered suitable for further evaluation due to its weak activity in both assays, which is below our laboratory thresholds of required larvicidal activity greater than $80 \%$ at $0.1 \mu \mathrm{g} / \mu \mathrm{L}$ and/or $>80 \%$ mortality in adult topical assays. However, plant extracts are often considered less harmful to the environment and are perceived as more natural. These natural products represent possible alternatives to current control methods. Previous studies by our research group revealed that the PR strain of Ae. aegypti was highly resistant to permethrin compared with the ORL strain in topical adult assays [41,42]. Norris et al. [43] highlighted that plant essential oils could complement or synergize pyrethroids. Future work with combinations of pyrethroids and plant essential oils needs to be done to determine the viability of use in integrated pest management strategies. Therefore, plant oils might offer potential alternatives to reduce resistance in mosquito populations.

In short-range attraction bioassays with male $C$. capitata, there were significant differences in behavioral response to the five essential oil treatments $(F=8.509$; $\mathrm{df}=4,20$; $p<0.001$; Figure 2). As seen in previous studies [44-47], highest attraction was observed with TTO (tea tree oil) [44]. Attraction to MCEO was comparable to that observed with TREO (Tetradenia riparia essential oil), a strong attractant [46], but also comparable to that observed with BTEO (blue tansy essential oil), a milder attractant [47]. However, attraction to MCEO was significantly greater than that observed with MGEO (mastic gum essential oil), a weak attractant [45], and significantly less than that observed with TTO, the best essential oil attractant identified to date [44-47]. The combined results indicate that MCEO is a moderately strong attractant for male C. capitata.

Previous chemical analyses indicated that the major components in the highly attractive TTO consisted of terpinen-4-ol (41.8\%), $\gamma$-terpinene $(15.5 \%), p$-cymene $(11.9 \%)$, $\alpha$-terpineol (5.0\%), $\alpha$-terpinene (3.9\%), 1,8-cineole (3.5\%), $\alpha$-pinene $(2.9 \%)$, and terpinolene $(2.8 \%)$ [44]. Principal components identified from TREO consisted of fenchone (15\%), $\delta$-cadinene (11\%), 14-hydroxy- $\beta$-caryophyllene (8\%), and tau-cadinol (7\%) [46]. The current study reports the major constituents of MCEO as linalool (19\%), geranial (16\%), citronellal $(14 \%)$, neral $(14 \%)$, and sabinene (12\%). Since none of these attractive essential oils have major chemical components in common, it is highly likely that a combination of these oils may result in additive or synergistic attraction of male C. capitata, as has been observed with multi-component lures for other agricultural pests [48]. Future research is warranted to evaluate efficacy of various combinations of attractive essential oils for improved detection of C. capitata under field conditions. 


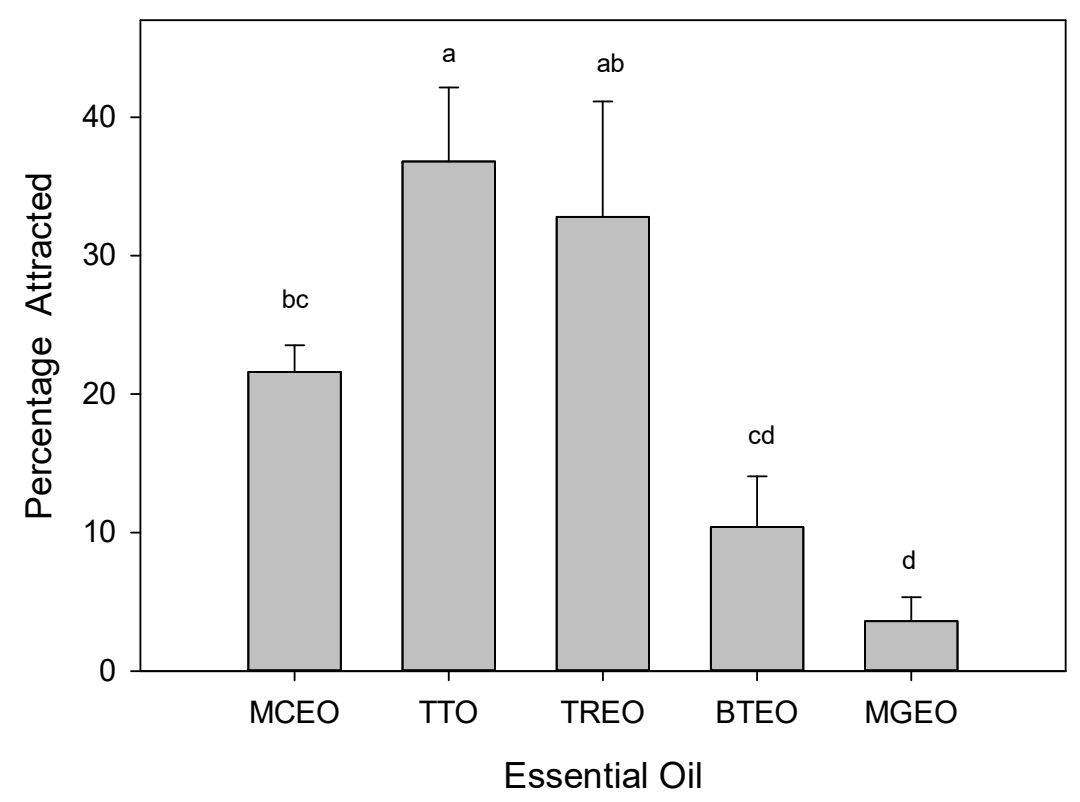

Figure 2. Attraction (mean $\pm \mathrm{SE}$ ) of male Mediterranean fruit fly, Ceratitis capitata, to five essential oils presented in short-range attraction bioassays. Response observed with Magnolia citrata essential oil (MCEO) was compared with response to two known strong attractants, tea tree oil (TTO) [44], and Tetradenia riparia essential oil (TREO) [46], and two mild attractants, blue tansy essential oil (BTEO) [47] and mastic gum essential oil (MGEO) [45]. Bars topped with the same letter are not significantly different (Tukey HSD mean separation, $p<0.05$ ).

\section{Materials and Methods}

\subsection{Plant Material}

Magnolia citrata leaves were collected from Ha Giang Province, Northwestern Vietnam. The GPS was recorded as $23^{\circ} 03^{\prime} 20^{\prime \prime} \mathrm{N} 105^{\circ} 05^{\prime} 48^{\prime \prime} \mathrm{E}$, and plant material all collected from a single tree. The plant specimen was identified by Mrs. Tu Bao Ngan. A voucher specimen has been deposited at the herbarium of Vietnam National Museum of Nature (VNMN).

\subsection{Essential Oil Isolation}

The harvested leaves $(900 \mathrm{~g})$ were subject to hydrodistillation using a Clevenger apparatus (Thermo Fisher Scientific, Waltham, MA, USA) for $3 \mathrm{~h}$. The slightly yellow oil was dried over anhydrous sodium sulfate to remove any trace of water and stored in sealed glass vials at $4{ }^{\circ} \mathrm{C}$ until further analysis. The yield was calculated as $0.38 \%$ according to the volume of obtained MCEO and was expressed on a fresh weight basis $(v / w)$.

\subsection{GC-MS Analysis}

The MCEO was diluted in methylene chloride in a 1:1000 ratio for analysis by GC-MS using an Agilent 5975B (Agilent Technologies, Santa Clara, CA, USA) system equipped with a DB5-MS column (Agilent Technologies, Santa Clara, CA, USA). The carrier gas was helium, with a flow rate of $1.3 \mathrm{~mL} \mathrm{~min}^{-1}$. GC oven temperature was kept at $45{ }^{\circ} \mathrm{C}$ for $1 \mathrm{~min}$ and increased to $94{ }^{\circ} \mathrm{C}$ at a rate of $4{ }^{\circ} \mathrm{C} \mathrm{min}-1$, then increased to $180{ }^{\circ} \mathrm{C}$ at a rate of $2{ }^{\circ} \mathrm{C} \mathrm{min}{ }^{-1}$. The PTV injector temperature was $200^{\circ} \mathrm{C}$. Mass spectra were recorded at $70 \mathrm{eV}$. Mass range was $m / z 35$ to 450 , ion source temperature was $230^{\circ} \mathrm{C}$, and the scan rate was $2.8 \mathrm{~s}^{-1}$.

\section{Identification of Components}

Using MassHunter software (B.07.02, Agilent Technologies, Santa Clara, CA, USA), the percentages of each component were calculated based on total ion current without standardization, by means of the chromatographic peak area normalization method. The MCEO components were identified by comparison of their relative indices to $C_{8}-C_{22}$ 
$n$-alkanes that were calculated on a nonpolar DB-5MS column according to the method of van den Dool and Kratz [49], authenticated samples ((Z)-3-hexen-1-ol (Cas \# 928-96-1, Sigma-Aldrich, St. Louis, MO, USA), $\alpha$-pinene (Cas \# 80-56-8, Sigma-Aldrich, St. Louis, MO, USA), sabinene (Cas \# 3387-41-5, Sigma-Aldrich, St. Louis, MO, USA), $\beta$-pinene (Cas \# 18172-67-3, Sigma-Aldrich, St. Louis, MO, USA), 6-methyl-5-hepten-2-one (Cas \# 110-93-0, Sigma-Aldrich, St. Louis, MO, USA), myrcene (Cas \# 123-35-3, Sigma-Aldrich, St. Louis, MO, USA), $p$-cymene (Cas \# 99-87-6, Sigma-Aldrich, St. Louis, MO, USA), limonene (Cas \# 5989-27-5, Florida Chem. Co., Winter Haven, FL, USA), 1,8-cineole (Cas \# 470-82-6, Fluka Chemical Co., Buchs, SG, Switzerland), mixture of (Z)- and (E)- $\beta$-ocimene (Cas \# 13877-91-3, Sigma-Aldrich, St. Louis, MO, USA), $\gamma$-terpinene (Cas \# 99-85-4, Sigma-Aldrich, St. Louis, MO, USA), mixture of cis- and trans-linalool oxide (Cas \# 60047-17-8, SigmaAldrich, St. Louis, MO, USA), linalool (Cas \# 78-70-6, Sigma-Aldrich, St. Louis, MO, USA), mixture of cis- and trans-p-menth-2-en-1-ol (product \# 3361 Synergy Semiochemicals Corp., Burnaby, BC, Canada), terpinen-4-ol (Cas \# 20126-76-5, Sigma-Aldrich, St. Louis, MO, USA), $\alpha$-terpineol (Cas \# 10482-56-1, Sigma-Aldrich, St. Louis, MO, USA), piperitone (Cas \# 89-81-6, Tokyo Chemical Industry Co., Ltd., Tokyo, Japan), $\beta$-caryophyllene (Cas \# Cas \# 87-44-5, Sigma-Aldrich, St. Louis, MO, USA), $\alpha$-humulene (Cas \# 6753-98-6, Sigma-Aldrich, St. Louis, MO, USA), alloaromadendrene (Cas \# 25246-27-9, Sigma-Aldrich, St. Louis, MO, USA), and caryophyllene oxide (Cas \# 1139-30-6, Sigma-Aldrich, St. Louis, MO, USA)], and by correlating mass spectra to databases of Adams library [33], NIST 17 [34], Wiley 11 [35], MassFinder terpenoids library [36], Flavors and Fragrances of Natural and Synthetic Compounds 3 (FFNSC 3) [37], and our own library "SHRS Essential Oil Constituents-DB5-MS" [50].

\subsection{Biologicaal Activities}

\subsubsection{Mosquito Assays}

Two strains of Aedes aegypti were used for bioassays: Orlando 1952 strain (ORL) and Puerto Rico strain (PR). Mosquitoes were reared following standard procedures at the USDA-ARS Center for Medical, Agricultural, and Veterinary Entomology (CMAVE) in Gainesville, FL, USA [51,52]. Since pyrethroid resistance is common in Ae. aegypti, we included adulticidal assays using the strongly resistant PR strain [53]. Newly emerged mosquitoes were maintained on $10 \%$ sugar water and kept in laboratory cages at an ambient temperature of $28 \pm 1{ }^{\circ} \mathrm{C}$ and $\mathrm{RH}$ of $35-60 \%$.

\subsubsection{Larvicidal Bioassay}

Larvicidal activity was assayed against 1st instar Ae. aegypti (ORL strain) as described previously [51,52]. Briefly, the MCEO was diluted in dimethyl sulfoxide (DMSO, Cas\# 67-68-5, Sigma-Aldrich Inc., St. Louis, MO, USA) to make $100 \mu \mathrm{g} / \mu \mathrm{L}$ and assayed in four different concentrations $(1.0,0.5,0.25$, and $0.1 \mu \mathrm{g} / \mu \mathrm{L})$ in a final volume of $200 \mu \mathrm{L}$ of larval rearing media into 96-well plates. Mortality was recorded after $24 \mathrm{~h}$ of exposure. Larva were considered dead if they did not move during observation or after swirling the contents of the well. Three replicates were conducted on consecutive days. Technicalgrade permethrin (Chem Service, West Chester, PA, USA) was used as a positive control at $31 \mathrm{pg} / \mu \mathrm{L}$, and DMSO was used as the negative control in all assays.

\subsubsection{Adulticidal Bioassay}

Females of Ae. aegypti (ORL and PR strains), 3-6 days post-emergence, were used in toxicity assays as described earlier [42,51-53]. Mosquitoes were briefly anesthetized at $4{ }^{\circ} \mathrm{C}$ and then sorted by sex. Females were used for all replicate tests. Compounds were diluted from a $100 \mu \mathrm{g} / \mu \mathrm{L}$ stock in DMSO into a $10 \mu \mathrm{g} / \mu \mathrm{L}$ working stock in acetone. A $0.5 \mu \mathrm{L}$ droplet of each working stock was applied to individual mosquitoes (15-20 per dose). A negative control of acetone (Cas \# 67-64-1, Sigma-Aldrich Inc., St. Louis, MO, USA) and positive control of permethrin $(0.69 \mathrm{ng} / \mu \mathrm{L})$ (Chem Service, West Chester, PA, USA) near the $\mathrm{LD}_{50}$ of the ORL1952 strain was included in each assay. Mortality was scored at $24 \mathrm{~h}$ after 
application, and data were corrected for background mortality with Abbott's correction if mortality in controls was between 10-20\%. Three replicates of the standard adult topical screening bioassay were conducted with 20 female mosquitoes at each dose.

\subsubsection{Fruit Fly Assay}

Experimental insects consisted of sterile male C. capitata obtained from the Programa Moscamed mass rearing facility in El Pino, Guatemala. Flies were irradiated as pupae two days prior to eclosion with $95 \mathrm{~Gy}$ of gamma radiation from a ${ }^{60} \mathrm{Co}$ source. Irradiated pupae were shipped initially to the USDA-APHIS Medfly Project in Sarasota, FL, USA, and then to the USDA-ARS Subtropical Horticulture Research Station (SHRS) in Miami, FL, USA. Flies were reared using established protocols [44,47] and used in bioassays when sexually mature (5-10 days old).

\section{Short-Range Attraction Bioassay}

Laboratory bioassays were conducted using methods similar to those reported previously [45-47]. Tests were performed using small screen cages $(20.3 \times 20.3 \times 20.3 \mathrm{~cm})$ into which 50 flies were introduced $1 \mathrm{~h}$ before the start of an experiment. Experiments were initiated by introducing a Petri dish (53 $\mathrm{mm}$ diameter $12 \mathrm{~mm}$ height) containing essential oil samples applied to a filter paper disk (Whatman \#1, $3.5 \mathrm{~cm}$ diameter). Each sample consisted of $10 \mu \mathrm{L}$ of a $10 \%$ dilution in acetone. To determine relative attraction to $\mathrm{MCEO}$, bioassays were performed with several control essential oils for comparison. Treatments consisted of MCEO, TTO (tea tree oil, derived from Melaleuca alternifolia (Maiden and Betche) Cheel., [44], TREO (Tetradenia riparia (Hochst.) Codd essential oil, [46]), BTEO (blue tansy essential oil, derived from Tanacetum annuum L., [47]), and MGEO (mastic gum essential oil, derived from Pistacia lentiscus L. var. chia, [45]). TTO and TREO are known to be strong attractants of male $C$. capitata and BTEO and MGEO are mild attractants. Tests were run for $30 \mathrm{~min}$; results were recorded initially as the number of flies within a Petri dish, which was then converted to percentage of flies attracted. Tests were replicated five times, and the results were analyzed by ANOVA followed by mean separation with Tukey test $(p<0.05)$ (Systat Software Inc.: San Jose, CA, USA) [54]).

\section{Conclusions}

Plant extracts and oils provide complementary ways of managing pests and diseases especially in tropical and subtropical regions. Due to the adverse effects of synthetic insecticides on the environment and human health, it is necessary to develop alternative control strategies to reduce the use of insecticides. In the present study, for the first time, we investigated the leaf essential oil of Magnolia citrata from Vietnam and its biological activity against two major insect pests of agricultural, medical and veterinary importance. Although MCEO exhibited weak toxicity against 1 st instar larvae and adult female Ae. aegypti, the oil showed a moderately strong attraction to sterile male medfly $C$. capitata as compared to a known strong attractant for medfly, tea tree oil (Melaleuca alternifolia). The oxygenated monoterpenes dominated in the MCEO and aliphatic aldehydes represented over threequarters of the total composition. The presence of aliphatic aldehydes in high concentration might reduce the captures of medflies. However, additional experiments may be required to determine whether aliphatic compounds are responsible for the moderate activity and whether the combination of MCEO with other plant essential oils, or essential oil components, can enhance the effectiveness of sterile male of C. capitata. In addition, combination blends should be tested in the field to ensure their efficacy.

Author Contributions: Conceptualization, N.T.; A.S.E., and P.E.K.; methodology, N.T.; A.S.E., and P.E.K.; software, P.E.K.; investigation, N.A.L.-D.; N.T.; A.S.E.; D.H.N., and P.E.K.; resources, N.A.L.-D.; N.T.; A.S.E.; D.H.N., and P.E.K.; data curation, N.T.; A.S.E., and P.E.K.; writing-original draft preparation, N.T.; N.A.L.-D.; A.S.E., and P.E.K.; writing—review and editing, N.T.; A.S.E., and P.E.K.; visualization, N.T. and N.A.L.-D.; supervision, P.E.K.; project administration, A.S.E. and P.E.K.; 
funding acquisition, A.S.E. and P.E.K. All authors have read and agreed to the published version of the manuscript.

Funding: This study was supported by a grant from the Deployed War-Fighter Protection (DWFP) Research Program through the U.S. Department of Defense through the Armed Forces Pest Management Board (AFPMB); and the United States Department of Agriculture (Project Number: 6038-22000-00700-D).

Institutional Review Board Statement: Not applicable.

Informed Consent Statement: Not applicable.

Data Availability Statement: Data is contained within the article.

Acknowledgments: Neil Sanscrainte (USDA-ARS, CMAVE, Gainesville, FL, USA); Jessica Louton (USDA-ARS, CMAVE, Gainesville, FL, USA); Micah Gill (USDA-ARS, SHRS, Miami, FL, USA); Monica Blanco (USDA-ARS, SHRS, Miami, FL, USA); Elena Schnell (USDA-ARS, SHRS, Miami, FL, USA); Bao Ngan Tu (Vietnam National Museum of Nature and Vietnam Academy of Sciences and Technology, Hanoi, Vietnam), Bui Văn Hương (Vietnam National Museum of Nature and Vietnam Academy of Sciences and Technology, Hanoi, Vietnam), and Patrick Arpino (ENSCP, Chime Paris Tech, UMR CNRS, Paris, France). We also acknowledge Aime Vazquez (USDA-ARS, SHRS, Miami, FL, USA) and Xiangbing Yang (USDA-ARS, SHRS, Miami, FL, USA) for proving critical reviews of an earlier version of this manuscript. We also thank journal editors and reviewers for helpful suggestions.

Conflicts of Interest: The authors declare no conflict of interest. Mention of trade names or commercial products in this publication is solely for the purpose of providing specific information and does not imply recommendation or endorsement by the U.S. Department of Agriculture. USDA is an equal opportunity provider and employer.

Sample Availability: MCEO is available from N.A.L.-D.

\section{References}

1. Samsidar, A.; Siddiquee, S.; Shaarani, S.M. A review of extraction, analytical and advanced methods for determination of pesticides in environment and foodstuffs. Trends Food Sci. Technol. 2018, 71, 188-201. [CrossRef]

2. Lengai, G.M.W.; Muthomi, J.W.; Mbega, E.R. Phytochemical activity and role of botanical pesticides in pest management for sustainable agricultural crop production. Sci. Afr. 2020, 7, e00239. [CrossRef]

3. Rani, L.; Thapa, K.; Kanojia, N.; Sharma, N.; Singh, S.; Grewal, A.S.; Srivastav, A.L.; Kaushal, J. An extensive review on the consequences of chemical pesticides on human health and environment. J. Clean. Prod. 2021, 283, 124657. [CrossRef]

4. Jepson, P.C.; Murray, K.; Bach, O.; Bonilla, M.A.; Neumeister, L. Selection of pesticides to reduce human and environmental health risks: A global guideline and minimum pesticides list. Lancet Planet. Health 2020, 4, e56-e63. [CrossRef]

5. Van Den Berg, H.; Gu, B.; Grenier, B.; Kohlschmid, E.; Al-Eryani, S.; Bezerra, H.S.D.S.; Nagpal, B.N.; Chanda, E.; Gasimov, E.; Velayudhan, R.; et al. Pesticide lifecycle management in agriculture and public health: Where are the gaps? Sci. Total. Environ. 2020, 742, 140598. [CrossRef]

6. Dinesh, D.S.; Kumari, S.; Kumar, V.; Das, P. The potentiality of botanicals and their products as an alternative to chemical insecticides to sandflies (Diptera: Psychodidae): A review. J. Vector Borne Dis. 2014, 51, 1-7. [PubMed]

7. Senthil-Nathan, S. A Review of Resistance Mechanisms of Synthetic Insecticides and Botanicals, Phytochemicals, and Essential Oils as Alternative Larvicidal Agents Against Mosquitoes. Front. Physiol. 2020, 10, 1591. [CrossRef]

8. Shah, F.; Razaq, M.; Ali, Q.; Shad, S.A.; Aslam, M.; Hardy, I.C.W. Field evaluation of synthetic and neem-derived alternative insecticides in developing action thresholds against cauliflower pests. Sci. Rep. 2019, 9, 7684. [CrossRef]

9. Hikal, W.M.; Baeshen, R.S.; Ahl, H.A.S.-A. Botanical insecticide as simple extractives for pest control. Cogent Biol. 2017, 3, 1404274. [CrossRef]

10. Vu, L.V.; Vu, C.Q. Diversity pattern of butterfly communities (Lepidoptera, Papilionoidae) in different habitat types in a tropical rain forest of southern Vietnam. Biodivers. Conserv. 2003, 12, 1099-1111. [CrossRef]

11. Van, Y.T.; Cochard, R. Tree species diversity and utilities in a contracting lowland hillside rainforest fragment in Central Vietnam. For. Ecosyst. 2017, 4, 9. [CrossRef]

12. Hung, D.V.; Potokin, A.F. Diversity of Plant Species Composition and Forest Vegetation Cover of Dong Nai Culture and Nature Reserve, Vietnam. IOP Conf. Ser. Earth Environ. Sci. 2019, 316, 012009. [CrossRef]

13. Mohammed, A.; Chadee, D.D. Effects of different temperature regimens on the development of Aedes aegypti (L.) (Diptera: Culicidae) mosquitoes. Acta Trop. 2011, 119, 38-43. [CrossRef] 
14. Al-Massarani, S.; El-Shaibany, A.; Tabanca, N.; Ali, A.; Estep, A.S.; Becnel, J.J.; Goger, F.; Demirci, B.; El-Gamal, A.; Baser, K.H.C. Assessment of selected Saudi and Yemeni plants for mosquitocidal activities against the yellow fever mosquito Aedes aegypti. Saudi Pharm. J. 2019, 27, 930-938. [CrossRef]

15. Niogret, J.; Montgomery, W.S.; Kendra, P.E.; Heath, R.R.; Epsky, N.D. Attraction and electroantennogram responses of male Mediterranean fruit fly to volatile chemicals from Persea, Litchi and Ficus Wood. J. Chem. Ecol. 2011, 37, 483-491. [CrossRef]

16. Papadopoulos, N.T. Fruit Fly Invasion: Historical, Biological, Economical Aspects and Management. In Trapping and the Detection, Control, and Regulation of Tephritid Fruit Flies, 1st ed.; Shelly, T., Epsky, N.D., Jang, E.B., Reyes-Flores, J., Vargas, R., Eds.; Springer: New York, NY, USA, 2014; pp. 219-252.

17. Vargas, R.I.; Leblanc, L.; Pinero, J.C.; Hoffman, K.M. Male Annihilation, Past, Present, and Future. In Trapping and the Detection, Control, and Regulation of Tephritid Fruit Flies, 1st ed.; Shelly, T., Epsky, N.D., Jang, E.B., Reyes-Flores, J., Vargas, R., Eds.; Springer: New York, NY, USA, 2014; pp. 493-511.

18. Kim, S.; Park, C.-W.; Kim, Y.-D.; Suh, Y.; Suh, Y.-D.K. Phylogenetic relationships in family Magnoliaceae inferred from ndhF sequences. Am. J. Bot. 2001, 88,717-728. [CrossRef]

19. Cires, E.; De Smet, Y.; Cuesta, C.; Goetghebeur, P.; Sharrock, S.; Gibbs, D.; Oldfield, S.; Kramer, A.; Samain, M.-S. Gap analyses to support ex situ conservation of genetic diversity in Magnolia, a flagship group. Biodivers. Conserv. 2013, 22, 567-590. [CrossRef]

20. Ho, K.-Y.; Tsai, C.-C.; Chen, C.-P.; Huang, J.-S.; Lin, C.-C. Antimicrobial activity of honokiol and magnolol isolated from Magnolia officinalis. Phytother. Res. 2001, 15, 139-141. [CrossRef] [PubMed]

21. Zhao, X.; Li, F.; Sun, W.; Gao, L.; Kim, K.S.; Kim, K.T.; Cai, L.; Zhang, Z.; Zheng, Y. Extracts of Magnolia Species-Induced Prevention of Diabetic Complications: A Brief Review. Int. J. Mol. Sci. 2016, 17, 1629. [CrossRef] [PubMed]

22. Sarrica, A.; Kirika, N.; Romeo, M.; Salmona, M.; Diomede, L. Safety and Toxicology of Magnolol and Honokiol. Planta Med. 2018, 84, 1151-1164. [CrossRef] [PubMed]

23. Miyazawa, M.; Ishikawa, Y.; Kasahara, H.; Yamanaka, J.-I.; Kameoka, H. An insect growth inhibitory lignan from flower buds of Magnolia fargesii. Phytochemistry 1994, 35, 611-613. [CrossRef]

24. Kelm, M.A.; Nair, M.G.; Schutzki, R.A. Mosquitocidal Compounds from Magnolia salicifolia. Int. J. Pharmacogn. 1997, 35, 84-90. [CrossRef]

25. Ali, A.; Tabanca, N.; Demirci, B.; Raman, V.; Budel, J.M.; Baser, K.H.C.; Khan, I.A. Insecticidal and Biting Deterrent Activities of Magnolia grandiflora Essential Oils and Selected Pure Compounds against Aedes aegypti. Molecules 2020, 25, 1359. [CrossRef] [PubMed]

26. Flores-Estevez, N.; Vasquez-Morales, S.G.; Cano-Medina, T.; Sanchez-Velasquez, L.R.; Noa Carrazana, J.C.; Diaz-Fleischer, F. Insecticidal activity of raw extracts from Magnolia dealbata Zucc on a tephritidae pest. J. Environ. Sci. Health B. 2013, 48, 585-589. [CrossRef]

27. Vasquez-Morales, S.G.; Flores-Estevez, N.; Sanchez-Velasquez, L.R.; Pineda-Lopez, M.D.R.; Viveros-Viveros, H.; Diaz-Fleischer, F. Bioprospecting of botanical insecticides: The case of ethanol extracts of Magnolia schiedeana Schltl. applied to a Tephritid, fruit fly Anastrepha ludens Loew. J. Entomol. Zool. 2015, 3, 1-5.

28. Global Biodiversity Information Facility. 2021. Available online: https:/ /www.gbif.org/species/3153028 (accessed on 14 January 2021).

29. The Plant List. 2013. A Working List of All Known Plant Species. Available online: http://www.theplantlist.org/tpl/record/ kew-348947 (accessed on 14 January 2021).

30. Wheeler, L.; Rivers, M.C.; Khela, S. Magnolia citrata. The IUCN Red List of Threatened Species. Available online: http: / / dx.doi.org/10.2305/IUCN.UK.2014-3.RLTS.T191871A2011039.en (accessed on 31 March 2021).

31. Ngoc Anh, L.-D.; Graduate University of Science and Technology, Vietnam Academy of Science and Technology (VAST), Hanoi, Vietnam; Vietnam National Museum of Nature, Vietnam Academy of Science and Technology (VAST), Hanoi, Vietnam. Personal communication, 30 March 2021.

32. Huong, B.V.; Ngan, T.B.; Ngoc Anh, L.D.; Tao, N.T. Preliminary study on chemical constituent of essential oil from the leaves of Michelia citrata (Noot. \& Chalenglin) Q.N.Vu \& N.H. Xia collected in Quan Ba District, Ha Giang Province. J. Sci. Technol. 2014, 30, 337-340.

33. Adams, R.P. Identification of Essential Oil Components by Gas Chromatography/Mass Spectrometry, 4th ed.; Allured Publishing Corporation: Carol Stream, IL, USA, 2007.

34. NIST. 17 Mass Spectrometer database, NIST/EPA/NIH. In NIST/EPA/NIH Mass Spectral Library; National Institute of Standards and Technology: Gaithersburg, MD, USA; Department of Commerce: Washington, DC, USA, 2017.

35. Wiley. Wiley Registry of Mass Spectral Data, 11th ed.; Wiley: Hoboken, NJ, USA, 2017.

36. Koenig, W.A.; Joulain, D.; Hochmuth, D. GC/MS Library: Terpenoids and Related Constituents of Essential Oils; Library of MassFinder: 2004. Available online: https:/ / massfinder.com (accessed on 22 March 2021).

37. Wiley. Flavors and Fragrances of Natural and Synthetic Compounds 3 (FFNSC 3), Mass Spectral Database; Wiley: Hoboken, NJ, USA, 2015.

38. Pandey, S.K.; Tandon, S.; Ahmad, A.; Singh, A.K.; Tripathi, A.K. Structure-activity relationships of monoterpenes and acetyl derivatives against Aedes aegypti (Diptera: Culicidae) larvae. Pest Manag. Sci. 2013, 69, 1235-1238. [CrossRef]

39. Waliwitiya, R.; Kennedy, C.J.; Lowenberger, C.A. Larvicidal and oviposition-altering activity of monoterpenoids, trans-anethole and rosemary oil to the yellow fever mosquito Aedes aegypti (Diptera: Culicidae). Pest Manag. Sci. 2009, 65, 241-248. [CrossRef] [PubMed] 
40. Cheng, S.; Lin, C.; Chung, M.; Liu, Y.; Huang, C.; Chang, S. Larvicidal activities of wood and leaf essential oils and ethanolic extracts from Cunninghamia konishii Hayata against the dengue mosquitoes. Ind. Crop. Prod. 2013, 47, 310-315. [CrossRef]

41. Reid, W.R.; Thornton, A.; Pridgeon, J.W.; Becnel, J.J.; Tang, F.; Estep, A.; Clark, G.G.; Allan, S.; Liu, N. Transcriptional analysis of four family 4 P450s in a Puerto Rico strain of Aedes aegypti (Diptera: Culicidae) compared with an Orlando strain and their possible functional roles in permethrin resistance. J. Med. Entomol. 2014, 51, 605-615. [CrossRef]

42. Pridgeon, J.W.; Meepagala, M.M.; Becnel, J.J.; Clark, G.G.; Pereira, R.M.; Linthicum, K.J. Structure-activity relationships of 33 piperidines as toxicants against female adults of Aedes aegypti (Diptera: Culicidae). J. Med. Entomol. 2007, 44, 263-269. [CrossRef]

43. Norris, E.; Johnson, J.; Gross, A.; Bartholomay, L.; Coats, J. Plant essential oils enhance diverse pyrethroids against multiple strains of mosquitoes and inhibit detoxification enzyme processes. Insects 2018, 9, 132. [CrossRef] [PubMed]

44. Tabanca, N.; Niogret, J.; Kendra, P.E.; Epsky, N.D. TLC-based bioassay to isolate kairomones from tea tree essential oil that attract male mediterranean fruit flies, Ceratitis capitata (Wiedemann). Biomolecules 2020, 10, 683. [CrossRef]

45. Tabanca, N.; Nalbantsoy, A.; Kendra, P.E.; Demirci, F.; Demirci, B. Chemical characterization and biological activity of the mastic gum essential oils of Pistacia lentiscus var. chia from Turkey. Molecules 2020, 25, 2136. [CrossRef] [PubMed]

46. Blythe, E.K.; Tabanca, N.; Demirci, B.; Kendra, P.E. Chemical composition of essential oil from Tetradenia riparia and its attractant activity for mediterranean fruit fly, Ceratitis capitata. Nat. Prod. Commun. 2020, 15, 1-6. [CrossRef]

47. Stappen, I.; Wanner, J.; Tabanca, N.; Bernier, U.R.; Kendra, P.E. Blue tansy essential oil: Chemical composition, repellent activity against Aedes aegypti and attractant activity for Ceratitis capitata. Nat. Prod. Commun. 2021, 16, 1-8. [CrossRef]

48. Kendra, P.E.; Owens, D.; Montgomery, W.S.; Narvaez, T.I.; Bauchan, G.R.; Schnell, E.Q.; Tabanca, N.; Carrillo, D. $\alpha$-Copaene is an attractant, synergistic with quercivorol, for improved detection of Euwallacea nr. fornicatus (Coleoptera: Curculionidae: Scolytinae). PLoS ONE 2017, 12, e0179416. [CrossRef]

49. Van Den Dool, H.; Kratz, P.D. A generalization of the retention index system including linear temperature programmed gas-liquid partition chromatography. J. Chromatogr. 1963, 11, 463-471. [CrossRef]

50. Owens, D.; Kendra, P.E.; Tabanca, N.; Narvaez, T.I.; Montgomery, W.S.; Schnell, E.Q.; Carrillo, D. Quantitative analysis of contents and volatile emissions from $\alpha$-copaene and quercivorol lures, and longevity for attraction of Euwallacea nr. fornicatus in Florida. $J$. Pest Sci. 2019, 92, 237-252. [CrossRef]

51. Pridgeon, J.W.; Becnel, J.J.; Clark, G.G.; Linthicum, K.J. A high-throughput screening method to identify potential pesticides for mosquito control. J. Med. Entomol. 2009, 46, 335-341. [CrossRef]

52. Meepagala, K.M.; Becnel, J.J.; Estep, A.S. Phomalactone as the active constituent against mosquitoes from Nigrospora spherica. Agric. Sci. 2015, 6, 1195-1201. [CrossRef]

53. Estep, A.S.; Sanscrainte, N.D.; Waits, C.M.; Louton, J.E.; Becnel, J.J. Resistance status and resistance mechanisms in a strain of Aedes aegypti (Diptera: Culicidae) from Puerto Rico. J. Med Entomol. 2017, 54, 1643-1648. [CrossRef] [PubMed]

54. Systat Software. SigmaPlot for Windows, version 14.0; Systat Software, Inc.: San Jose, CA, USA, 2017. 